\title{
Oxidative Stress in Multiple Organ Damage in Hypertension, Diabetes and CKD, Mechanisms and New Therapeutic Possibilities
}

\author{
Tatsuo Shimosawa* et al. \\ Department of Clinical Laboratory, Faculty of Medicine, University of Tokyo \\ Japan
}

\section{Introduction}

Hypertension, diabetes, hypercholesterolemia and chronic kidney disease (CKD) lead to cardiovascular $(\mathrm{CV})$ events and cardiovascular death consists of main cause in mortality of those diseases. Understanding of pathophysiology that links them and CV events has been vigorously studied and several factors are believed to play roles such as NO, reninangiotensin system, and oxidative stress. It has been shown that those factors affect endothelial function and consequently organ circulation as well as function and viability of cells and organs. Despite overwhelming evidences in the consequences of experimental models of ROS-induced organ damage, large-scale clinical trials of former antioxidant therapies, such as vitamin $C$, vitamin $E$ or $\beta$-carotene, could not demonstrate satisfactory benefit to patients and they seemed to be harmful in some cases (Hennekens et al., 1996; Omenn et al., 1996; Virtamo et al., 1998; Hercberg et al., 1999; Lee et al., 1999; Yusuf et al., 2000; de Gaetano, 2001; Heart, 2002; Vivekananthan et al., 2003; Hercberg et al., 2004; KrisEtherton et al., 2004; Lonn et al., 2005). Several studies concluded that $\beta$-carotene supplementation increased the relative risk of death in patients with some types of cancer and had no benefit on patients with cardiovascular disease. Another study said vitamin E increased hemorrhagic stroke. Even antioxidant cocktails increased in all-cause motality (Omenn et al., 1996; Rosen et al., 2001a). So far, supplementation with vitamins C and E, either alone or in combination with each other or with other antioxidant vitamins, does not appear to be efficacious for the treatment of cardiovascular disease (Lonn et al., 2005). We investigated role of oxidative stress in consequences of multiple organ damages in mouse and possible new therapeutic agent.

\footnotetext{
* Tomoyo Kaneko², Xu Qingyou'1, Yusei Miyamoto ${ }^{3}$, Mu Shengyu², Hong Wang'2, Sayoko Ogura², Rika Jimbo², Bohumil Majtan², Yuzaburo Uetake², Daigoro Hirohama², Fumiko Kawakami-Mori², Toshiro Fujita ${ }^{2}$ and Yutaka Yatomi ${ }^{1}$

${ }^{1}$ Department of Clinical Laboratory, Faculty of Medicine, University of Tokyo, Japan

${ }^{2}$ Department of Endocrinology and Nephrology, Faculty of Medicinem, Japan

${ }^{3}$ Department of Integrated Biosciences, Graduate School of Frontier Sciences, University of Tokyo, Japan
} 


\section{Adrenomedullin}

\subsection{Cardiovascular effects}

Adrenomedullin is a 52-amino-acid peptide and was originally isolated from pheochromocytoma cell but is also produced and secreted in endothelial cells and potent hypotensive peptide (Shimosawa \& Fujita, 2005). We generated its deficient mice and proved that it is an endogenous antioxidants.

We examined the antioxidant properties of AM in both angiotensin II-salt (Shimosawa et al., 2002) and pulmonary hypertension models (Matsui et al., 2004). We showed that AMknockout mice had higher oxidative stress through 3 ways: the urinary excretion of oxidative stress markers, such as 8-hydroxydeoxyguanosine (Fig. 1a) and isoprostane (Fig. 1b) by ELISA method, the immunostaining of 3-nitrotyrosine to localize oxidative stress (Fig. 1c), and real-time oxidant production measurement by the electron spin resonance (ESR) method (Fig. 1d). Pathological changes in the heart, such as periarterial fibrosis and coronary artery occlusion, were prominent in the knockout mice, and further investigation revealed that high oxidative stress caused coronary artery damage in this model.

Fig. 1a

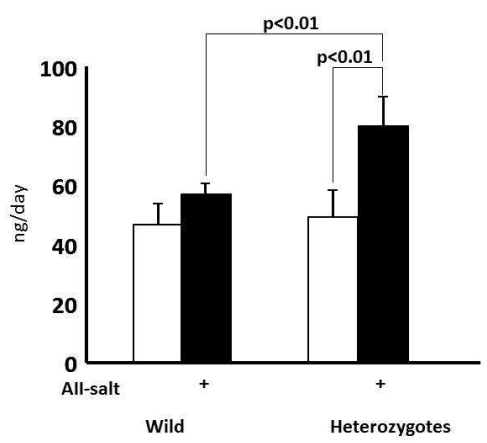

Fig. 1c

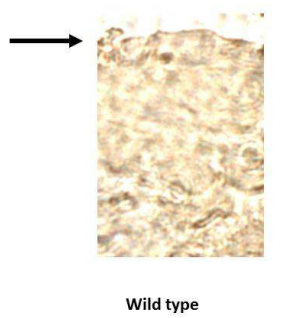

Fig. $1 \mathrm{~b}$

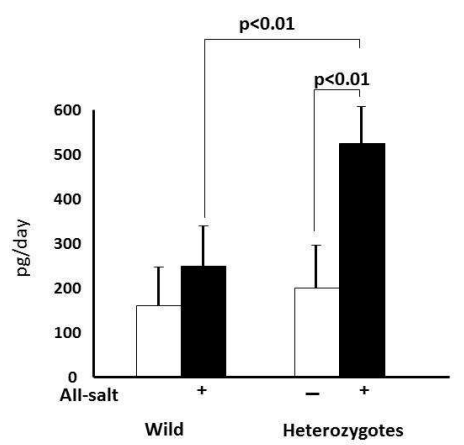

Fig. 1d
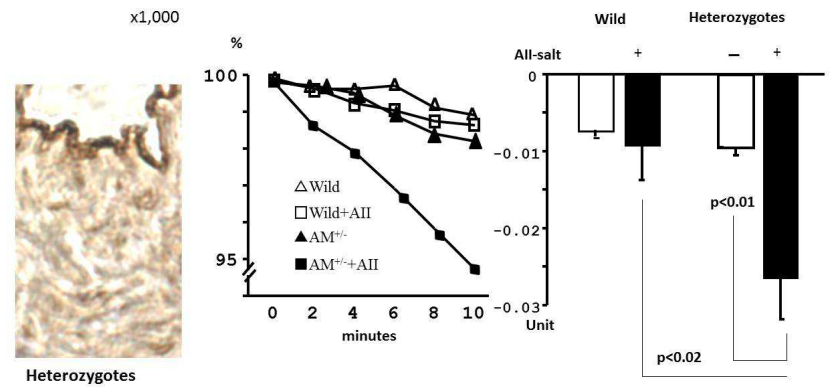

Fig. 1. Evaluation of oxidative stress in $\mathrm{AM}^{+/-}$mice after angiotensin II and salt loading. 
We measured urinary excretion of 8-OHdG (a) and isoprostane (b) as footsteps of oxidative stress in whole body. As for confirming local oxidative stress, we immunostained coronary artery with 3-nitrotyrosine (c) that reflects NO-related oxidative stress and is a good marker for oxidative stress at the endothelial layer (arrow). For evaluation of real time production of oxidative stress, we measured ESR signal in the heart (d). On the left of panel $d$, time dependent of decay of ESR signal were plotted and on the right panel, the decay ratio of ESR signal that reflects production of oxidative stress was calculated. All these data suggest angiotensin II and salt-loaded $\mathrm{AM}^{+/-}$mice has higher oxidative stress than wild type mice. Modified from Shimosawa et al. 2002.

Hypoxia is known to cause pulmonary hypertension and pulmonary vascular remodeling. With this model, evidence is accumulating that ROS are the upstream signals of chronic hypoxia-induced pulmonary vasoconstriction and the development of vascular remodeling. It has been reported that ROS generated by hypoxia can induce calcium release from sarcoplasmic reticulum stores, which is followed by pulmonary vasoconstriction (Waypa et al., 2002). Moreover, ROS activated several growth factors such as vascular endothelial growth factor and platelet-activating factor (PAF) (Hartung et al., 1983; Ono et al., 1992; Chandel et al., 1998), which induce vascular remodeling. In the early phase of hypoxic conditions, ROS may act as a trigger of this signaling cascade in the process of vascular remodeling. In our experiments, $10 \% \mathrm{O}_{2}$ conditions caused higher ROS in AM-knockout mice compared with wild-type mice. Concomitant with increased oxidative stress in the pulmonary artery, AM-knockout mice showed marked vascular remodeling and higher mortality (Matsui et al., 2004), which were reversed by AM supplementation or by treatment with 4-Hydroxy-2,2,6,6-tetramethyl-piperidine-N-oxyl (hydroxyl-TEMPO), a mimetic of superoxide dismutase. Based on this basic research, translational research studies have been conducted in patients with pulmonary hypertension, and potent therapeutic effects of inhaling AM have been reported (Nagaya et al., 2004). As the mortality among patients with pulmonary hypertension is high even treatment with nitric oxide and prostaglandins, AM, or other agents may be novel and promising agents for the treatment of these patients.

\subsection{Renal effects and possible role in CKD and diabetic kidney disease}

Renal dysfunction or chronic kidney disease (CKD) draws high interests among nephrologists as well as cardiologists and other specialities. There are several factors implicated to connect renal dysfunction and cardiovascular events, endothelial dysfunction, renin-angiotensin-aldosterone axis, oxidative stress, and unknown toxic agents. In order to investigate if renin-angiotensin axis and oxidative stress can be therapeutical target in CKD, we used AM knockout mice. We found increased oxidative stress and local reninangiotensin system in the ureter-obstructed kidney of AM knockout mice. Concordance with the increase of oxidative stress and renin-angiotensin system, severe interstitial fibrosis, and cell proliferation were prominent in AM-knockout mice. The interstitial fibrosis can be partly reversed by hydroxyl-TEMPO, angiotensin receptor blockers, or the systemic replacement of AM (unpublished observation). When dual treatment with angiotensin receptor blocker and hydroxyl-TEMPO were given, pathological changes are more effectively reversed compared with that by each agent alone. Angiotensin II is known to induce oxidative stress via activating NADPH oxidase and AM can block this pathway via 
c-Src (Liu et al., 2007). In the kidney, oxidative stress is generated not only by NADPH oxidase but from mitochondria and xanthine oxidase and thus AM or angiotensin II blocker alone therapy is not sufficient and together with hydroxyl-TEMPO that can totally block oxidative stress is effective.

Multiple lines of study have shown that diabetic patients have increased oxidative stress and the resultant organ damage (Rosen et al., 2001b). In turn, it is hypothesized that oxidative stress can induce diabetes by series of studies; oxidative stress impairs insulin internalization (Bertelsen et al., 2001), blocks insulin receptor substrate phosphorylation, impairs phosphoinositide-3 kinase activity (Najib \& Sanchez-Margalet, 2001), induces protein glycation and as a consequence of advanced glycation end-products-receptor binding that leads to cytotoxicity in pancreatic beta cells and reduces the translocation of glucose transporter type-4 (Rudich et al., 1997; Rudich et al., 1998). An in vivo study also showed that the administration of oxidative stress aggravated diabetes in diabetes-prone obese-Zucker rats (Laight et al., 2000). Antioxidan supplementation studies have shown conflicting resuts; some reported beneficial effects in endothelial function, retinal blood flow and renal function outcomes (Blum et al.; Ziegler et al., 2004; Lopes de Jesus et al., 2008), in contrast, the recent metaanalysis of antioxidants, vitamin $\mathrm{C}$ and $\mathrm{E}$, supplementation trials revealed ineffectiveness in glycemic control (Akbar et al., 2011). On the other hand, in clinical settings, diabetics have higher oxidative stress and AM levels (Hayashi et al., 1997), which led us to assume that AM is upregulated in order to antagonize oxidative stress. In fact, aged or angiotensin II-treated AM-knockout mice showed insulin resistance, and this was reversed by AM supplementation (Shimosawa et al., 2003; Xing et al., 2004) (Fig. 2). In this experiment, we showed that oxidative stress directly impaired insulin signaling by interfering with insulin receptor substrate 1 and 2 phosphorylations. By in vitro experiments, we found that oxidative stress not only impairs insulin signaling, but also reduces glucose transporter 4 transcription (unpublished observation).

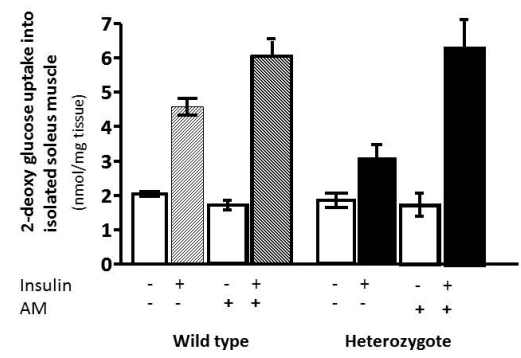

Fig. 2. Insulin resistance in skeletal muscle of aged $\mathrm{AM}^{+/-}$mice which was recovered by $\mathrm{AM}$ supplement.

Insulin resistance was measured by ex vivo experiments. Isolated soleus muscle was incubated with insulin and ${ }^{12} \mathrm{C}$-deoxyglucose. Deoxyglucose uptake was evaluated as insulin sensitivity. Aged male $\mathrm{AM}^{+/-}$mice (55 weeks old) showed insulin resistance and AM supplementation for a month successfully reversed insulin resistant state. Modified from Shimosawa et al. 2003. 
Recent clinical trial in diabetic CKD patients revealed bardoxolone methyl effectively improved in the estimated GFR independent from blood pressure which is the most important risk in CKD (Pergola et al., 2011). Also, it improved insulin resistance by increasing glucose uptake in skeletal muscle (Saha et al.), which is compatible with our findings in AM knockout mice as described above. Bardoxolone methyl is an oral antioxidant inflammation modulator and activates the Keap1-Nrf2 pathway. Keap1-Nrf2 pathway regulates inflammation and oxidative stress (Dinkova-Kostova et al., 2005) via increased expression of heme oxygenase 1 (Wu et al., 2011). This compound is so far the only clinically available antioxidants that show organ protective effect, however, it requires further assessment if bardoxolone methyl can prevent hard end-point such as cardiovascular events or mortality in CKD patients.

\section{Platinum nanoparticle}

In diabetic-CKD, possible clinical usefulness of bardoxolone methyl was shown as mentioned above, so far few antioxidant agents are proved to be effective in cardiovascular protection. Although in pulmonary hypertension AM showed its clinical usefulness by inhaling, AM is a peptide and its clinical use is limited due to its short half life. We next investigated the possible therapeutic effect of platinum-nano-particle.

In recent years, a few reports about new drug delivery system using nanotechnology have been released (Muro et al., 2006; Kajita et al., 2007; Shimizu et al., 2010). Among them platinum nanoparticles as both superoxide dismutase (SOD) mimetic and catalase mimetic (Kajita et al., 2007; Watanabe et al., 2009). In vivo experiments shows its effectiveness in smoking-induced lung damage (Onizawa et al., 2009) or stroke model mice (Takamiya et al.et al., 2011). Platinum nanoparticles (PAA-Pt) was administered intranasally, which were then exposed to cigarette smoking for 3 days. Cigarette smoking induced NFkappaB activation, and neutrophilic inflammation in the lungs of mice, and intranasal administration of PAA-Pt inhibited these changes. Moreover in in vitro experiments, treatment of alveolar-type-II-like A549 cells with PAA-Pt inhibited cell death after exposure to a cigarette smoke extract. Transient middle cerebral artery occlusion (tMCAO) and reperfusion model was used in this study. PAA-Pt was administered intravenously. PAA-Pt dramatically reduced oxidative stress in the brain and significantly improved the motor function and greatly reduced the infarct volume, especially in the cerebral cortex with preserved collagen IV and a remarkable suppression of MMP-9. By these acute models the antioxidant effect and concomitant organ protection by PAA-Pt were established. We investigated the chronic effect of PAA-Pt and studied if PAA-Pt reverse cardiovascular damage in metabolic syndrome model by eliminating ROS.

Metabolic syndrome model was established by angiotensin II and high salt diet on diabetic 8-week-old male $\mathrm{db} / \mathrm{db}$ mice. $10 \mu \mathrm{M}$ platinum nanoparticles were given orally. The oxidative stress was measured in two ways. First, the urinary excretion of isoprostane reflects the state of systemic oxidative stress. Ang II and salt loading increased isoprostane excretion in $\mathrm{db} / \mathrm{db}$ mice. PAA-Pt reduced isoprostane excretion, suggesting that PAA-Pt would be an effective antioxidant (Fig 3). Blood pressure was elevated by angiotensin II and high salt diet and PAA-Pt treatment did not have any effects on blood pressure and other metabolic biomarkers of mice. 


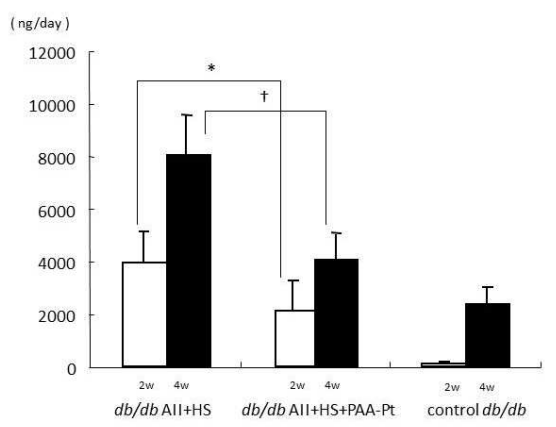

Fig. 3. PAA-Pt effect on oxidative stress

$\mathrm{Db} / \mathrm{db}$ mice were treated with angiotensin II and high salt diet and urinary isoprostane was measured as a marker of oxidative stress. PAA-Pt effectively reduced oxidative stress.

Consistent with AM knockout mice, angiotensin II and high salt diet induced pericoronary fibrosis in $\mathrm{db} / \mathrm{db}$ mice (Fig. 4a). The degree of deterioration of vascular damage was much severer in the $\mathrm{db} / \mathrm{db}$ mice than wild type mice. PAA-Pt therapy reversed the vascular damage in angiotensin II/salt loaded $\mathrm{db} / \mathrm{db}$ mice. The area of fibrous changes was calculated for each group (Fig $4 b$ ). The results of RT-PCR supported the aforesaid

a.

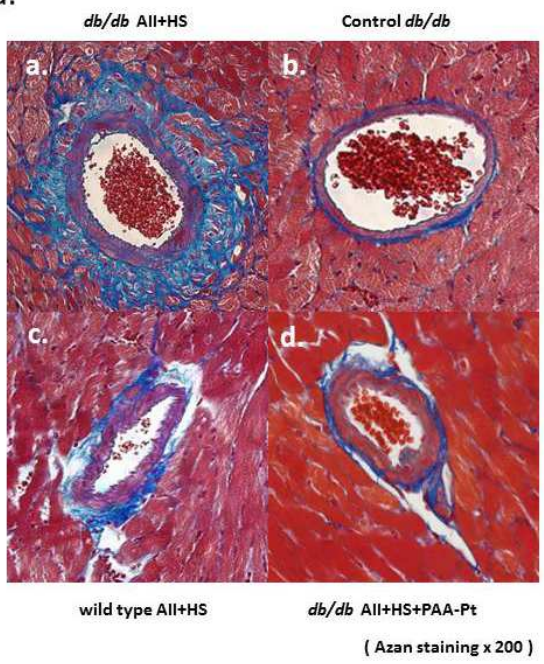

b.

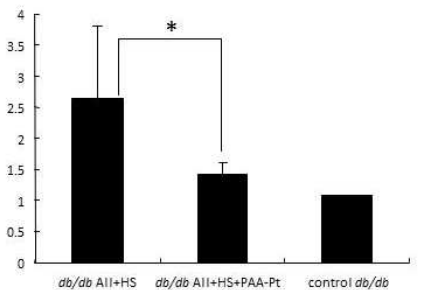

Fig. 4. Histopathological changes of $\mathrm{db} / \mathrm{db}$ mice by angiotensin II/high salt diet and effect of PAA-Pt. 
histopathological findings. We examined mRNA expression of ANP and procollagen type $\mathrm{I} \alpha$ in the heart as molecular markers of cardiac damage and we found that those molecular markers were apparently up-regulated by angiotensin II and salt loading (Fig 5). PAA-Pt reduced these markers expressions to the almost same extent with the control $\mathrm{db} / \mathrm{db}$ mice and these results support our findings in the histopathological examinations.

Pericoronary fibrosis were evaluated by Azan staining. Fibrosis was robust by angiotensin II and high salt diet and was reversed by PAA-Pt.

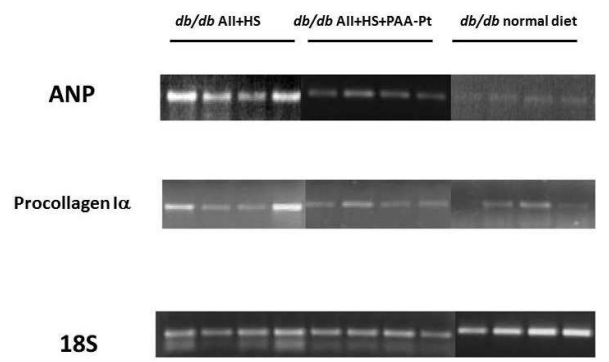

Fig. 5. Molecular markers for cardiac damage and fibrosis.

mRNA expression of ANP and procollagen type I were evaluated. Concomitant with figure 4 , angiotensin II and high salt diet aggravated cardiac damage and it was reversed by PAAPt.

PAA-Pt behaves as an SOD mimetic and possesses a catalase activity, then its efficacy can last longer than vitamin C (Kajita et al., 2007). It is mainly because the catalytic property of PAA-Pt which is distinguished from vitamin $C$ that is quickly consumed. Therefore we examined the effect of PAA-Pt in metabolic syndrome model mice to reduce oxidative stress and protect the cardiovascular system. Concordance with in vitro study, PAA-Pt effectually reduced ROS and prevented cardiovascular damage in hypertensive $\mathrm{db} / \mathrm{db}$ mice.

We found the extension of cardiovascular damages was much severer and the level of systemic oxidative stress, which was evaluated by urinary excretion of isoprostane, was much higher in $\mathrm{db} / \mathrm{db}$ mice. Then, it is indicated that the 'metabolic-syndrome-status' is equal to 'high-oxidative-stress-status' and this status seems to be the trigger of the vicious cycle of organ damage. Thus, the scavenging ROS would be a promising approach to preventing organ damage in metabolic syndrome.

PAA-Pt also has the possibility to solve the problems of former antioxidants as vitamin $\mathrm{C}, \mathrm{E}$ or $\beta$-carotene. It is said the one of the reasons why those former antioxidants would have failed to be effective against organ damage that they are short-acting and could not eliminate intracellular ROS, including mitochondrial ROS. PAA-Pt possesses long-lasting activity (means catalytic effect) and dual properties as SOD and catalase mimetics. The 
pharmacokinetics of PAA-Pt in detail have not been revealed yet that PAA-Pt should enter to systemic circulation from digestive apparatus, and be excreted from urine. Also we suggestively expect the novel antioxidant PAA-Pt enables to eliminate intracellular ROS. Further studies in pharmacokinetics and safety of PAA-Pt in chronic use are required. Specially, PAA-Pt contains platinum, which is sometimes toxic to the kidney, we must be careful about its nephrotoxicity before clinical applications. In site of some assignments such as its safety or full internal dynamism must be proven before clinical use, this novel agent will be certain way to open the door to interdisciplinary treatments between nanotechnology and medicine.

\section{Perspectives}

Piles of evidence accumulated that oxidative stress is a new therapeutic targets in preventing cardiovascular events and its risks. Among risks, hypertension, glucose metabolism and lipid accumulation in the vasculature are closely related with oxidative stress, however, some but not all antioxidant lower blood pressure or prevent atherosclerosis. Blood pressure is regulated by both circulating blood volume and vascular resistance and most of the data suggest that oxidative stress may affect vascular resistance but not blood volume, which can explain antioxidant therapy is not consistent in lowering blood pressure. For lipid disorders and consecutive atherosclerosis, oxidized LDL as well as its receptor is important. In mice LDL level are almost negligible however, oxidized LDL receptor such as LOX-1 overexpression leads to vascular damage (Inoue et al., 2005). It suggests that ligand regulation by targeting oxidative stress is not sufficient but we should consider receptor regulation as well. On the other hand, insulin resistance or glucose metabolism can be a good target of antioxidant therapy. Insulin signaling is impaired by oxidative stress and it is reversed by antioxidants. Our and others' basic trials as well as recent data by bardoxolone methyl are promising, although the optimal glucose regulation level to prevent cardiovascular complications in diabetes are still under debate. The 'lower the better' of blood glucose is controversial because of hypoglycemia induces poor prognosis in cardiovascular event, however, targeting oxidative stress recovers impairedinsulin resistance and does not stimulate insulin release, therefore, it would be safer than insulin replacement or insulin secretion stimulating agents such as sulphonylurea. Further clinical trials are required.

\section{Conclusion}

AM, PAA-PT or bardoxolone are possibly promising antioxidants in treating or reducing risks for chronic metabolic disease and organ damages. Other possible agents are also under investigations and novel technology will lead us to invent antioxidants with more efficacy and less side effect. Oxidative stress is indispensable for host defence and appropriate reduction of oxidative stress is required when considering antioxidants in clinical use.

\section{References}

Akbar S, Bellary S \& Griffiths HR. (2011). Dietary Antioxidant Interventions in Type 2 Diabetes Patients A Meta-analysis. Br J Diabetes Vasc Dis 11, 62-68. 
Bertelsen M, Anggard EE \& Carrier MJ. (2001). Oxidative stress impairs insulin internalization in endothelial cells in vitro. Diabetologia 44, 605-613.

Blum S, Vardi M, Brown JB, Russell A, Milman U, Shapira C, Levy NS, Miller-Lotan R, Asleh R \& Levy AP. Vitamin E reduces cardiovascular disease in individuals with diabetes mellitus and the haptoglobin 2-2 genotype. Pharmacogenomics 11, 675-684.

Chandel NS, Maltepe E, Goldwasser E, Mathieu CE, Simon MC \& Schumacker PT. (1998). Mitochondrial reactive oxygen species trigger hypoxia-induced transcription. Proc Natl Acad Sci U S A 95, 11715-11720.

de Gaetano G. (2001). Low-dose aspirin and vitamin E in people at cardiovascular risk: a randomised trial in general practice. Collaborative Group of the Primary Prevention Project. Lancet 357, 89-95.

Dinkova-Kostova AT, Liby KT, Stephenson KK, Holtzclaw WD, Gao X, Suh N, Williams C, Risingsong R, Honda T, Gribble GW, Sporn MB \& Talalay P. (2005). Extremely potent triterpenoid inducers of the phase 2 response: correlations of protection against oxidant and inflammatory stress. Proc Natl Acad Sci U S A 102, 4584-4589.

Hartung HP, Parnham MJ, Winkelmann J, Englberger W \& Hadding U. (1983). Platelet activating factor (PAF) induces the oxidative burst in macrophages. Int $J$ Immunopharmacol 5, 115-121.

Hayashi M, Shimosawa T, Isaka M, Yamada S, Fujita R \& Fujita T. (1997). Plasma adrenomedullin in diabetes. Lancet 350, 1449-1450.

Heart P, Study, Collaborative, Group. (2002). MRC/BHF Heart Protection Study of antioxidant vitamin supplementation in 20,536 high-risk individuals: a randomised placebo-controlled trial. Lancet 360, 23-33.

Hennekens CH, Buring JE, Manson JE, Stampfer M, Rosner B, Cook NR, Belanger C, LaMotte F, Gaziano JM, Ridker PM, Willett W \& Peto R. (1996). Lack of effect of long-term supplementation with beta carotene on the incidence of malignant neoplasms and cardiovascular disease. N Engl J Med 334, 1145-1149.

Hercberg S, Galan P, Preziosi P, Bertrais S, Mennen L, Malvy D, Roussel AM, Favier A \& Briancon S. (2004). The SU.VI.MAX Study: a randomized, placebo-controlled trial of the health effects of antioxidant vitamins and minerals. Arch Intern Med 164, 2335-2342.

Hercberg S, Preziosi P, Galan P, Faure H, Arnaud J, Duport N, Malvy D, Roussel AM, Briancon S \& Favier A. (1999). "The SU.VI.MAX Study": a primary prevention trial using nutritional doses of antioxidant vitamins and minerals in cardiovascular diseases and cancers. SUpplementation on VItamines et Mineraux AntioXydants. Food Chem Toxicol 37, 925-930.

Inoue K, Arai Y, Kurihara H, Kita T \& Sawamura T. (2005). Overexpression of lectin-like oxidized low-density lipoprotein receptor-1 induces intramyocardial vasculopathy in apolipoprotein E-null mice. Circ Res 97, 176-184.

Kajita M, Hikosaka K, Iitsuka M, Kanayama A, Toshima N \& Miyamoto Y. (2007). Platinum nanoparticle is a useful scavenger of superoxide anion and hydrogen peroxide. Free Radic Res 41, 615-626.

Kris-Etherton PM, Lichtenstein AH, Howard BV, Steinberg D \& Witztum JL. (2004). Antioxidant vitamin supplements and cardiovascular disease. Circulation 110, 637641. 
Laight DW, Desai KM, Anggard EE \& Carrier MJ. (2000). Endothelial dysfunction accompanies a pro-oxidant, pro-diabetic challenge in the insulin resistant, obese Zucker rat in vivo. Eur J Pharmacol 402, 95-99.

Lee IM, Cook NR, Manson JE, Buring JE \& Hennekens CH. (1999). Beta-carotene supplementation and incidence of cancer and cardiovascular disease: the Women's Health Study. J Natl Cancer Inst 91, 2102-2106.

Liu J, Shimosawa T, Matsui H, Meng F, Supowit SC, Dipette DJ, Ando K \& Fujita T. (2007). Adrenomedullin Inhibits Angiotensin II-Induced Oxidative Stress Via CskMediated Inhibition of Src Activity. Am J Physiol Heart Circ Physiol 292, H1714H1721.

Lonn E, Bosch J, Yusuf S, Sheridan P, Pogue J, Arnold JM, Ross C, Arnold A, Sleight P, Probstfield J \& Dagenais GR. (2005). Effects of long-term vitamin E supplementation on cardiovascular events and cancer: a randomized controlled trial. Jama 293, 1338-1347.

Lopes de Jesus CC, Atallah AN, Valente O \& Moca Trevisani VF. (2008). Vitamin C and superoxide dismutase (SOD) for diabetic retinopathy. Cochrane Database Syst Rev, CD006695.

Matsui H, Shimosawa T, Itakura K, Guanqun X, Ando K \& Fujita T. (2004). Adrenomedullin Can Protect Against Pulmonary Vascular Remodeling Induced by Hypoxia. Circulation 109, 2246-2251.

Muro S, Mateescu M, Gajewski C, Robinson M, Muzykantov VR \& Koval M. (2006). Control of intracellular trafficking of ICAM-1-targeted nanocarriers by endothelial $\mathrm{Na}+/ \mathrm{H}+$ exchanger proteins. Am J Physiol Lung Cell Mol Physiol 290, L809-817.

Nagaya N, Kyotani S, Uematsu M, Ueno K, Oya H, Nakanishi N, Shirai M, Mori H, Miyatake K \& Kangawa K. (2004). Effects of adrenomedullin inhalation on hemodynamics and exercise capacity in patients with idiopathic pulmonary arterial hypertension. Circulation 109, 351-356.

Najib S \& Sanchez-Margalet V. (2001). Homocysteine thiolactone inhibits insulin signaling, and glutathione has a protective effect. J Mol Endocrinol 27, 85-91.

Omenn GS, Goodman GE, Thornquist MD, Balmes J, Cullen MR, Glass A, Keogh JP, Meyskens FL, Valanis B, Williams JH, Barnhart S \& Hammar S. (1996). Effects of a combination of beta carotene and vitamin A on lung cancer and cardiovascular disease. N Engl J Med 334, 1150-1155.

Onizawa S, Aoshiba K, Kajita M, Miyamoto Y \& Nagai A. (2009). Platinum nanoparticle antioxidants inhibit pulmonary inflammation in mice exposed to cigarette smoke. Pulm Pharmacol Ther 22, 340-349.

Ono S, Westcott JY \& Voelkel NF. (1992). PAF antagonists inhibit pulmonary vascular remodeling induced by hypobaric hypoxia in rats. J Appl Physiol 73, 1084-1092.

Pergola PE, Raskin P, Toto RD, Meyer CJ, Huff JW, Grossman EB, Krauth M, Ruiz S, Audhya P, Christ-Schmidt H, Wittes J \& Warnock DG. (2011). Bardoxolone methyl and kidney function in CKD with type 2 diabetes. N Engl J Med 365, 327-336.

Rosen P, Nawroth PP, King G, Moller W, Tritschler HJ \& Packer L. (2001a). The role of oxidative stress in the onset and progression of diabetes and its complications: a summary of a Congress Series sponsored by UNESCO-MCBN, the American Diabetes Association and the German Diabetes Society. Diabetes Metab Res Rev 17, 189-212. 
Rosen P, Nawroth PP, King G, Moller W, Tritschler HJ \& Packer L. (2001b). The role of oxidative stress in the onset and progression of diabetes and its complications: a summary of a Congress Series sponsored by UNESCO-MCBN, the American Diabetes Association and the German Diabetes Society. Diabetes Metab Res Rev 17, 189-212.

Rudich A, Kozlovsky N, Potashnik R \& Bashan N. (1997). Oxidant stress reduces insulin responsiveness in 3T3-L1 adipocytes. Am J Physiol 272, E935-940.

Rudich A, Tirosh A, Potashnik R, Hemi R, Kanety H \& Bashan N. (1998). Prolonged oxidative stress impairs insulin-induced GLUT4 translocation in 3T3-L1 adipocytes. Diabetes 47, 1562-1569.

Saha PK, Reddy VT, Konopleva M, Andreeff M \& Chan L. (2010). The triterpenoid 2-cyano3,12-dioxooleana-1,9-dien-28-oic-acid methyl ester has potent anti-diabetic effects in diet-induced diabetic mice and Lepr(db/db) mice. J Biol Chem 285, 40581-40592.

Shimizu H, Hori Y, Kaname S, Yamada K, Nishiyama N, Matsumoto S, Miyata K, Oba M, Yamada A, Kataoka K \& Fujita T. (2010). siRNA-based therapy ameliorates glomerulonephritis. J Am Soc Nephrol 21, 622-633.

Shimosawa T \& Fujita T. (2005). Adrenomedullin and its related peptide. Endocr J 52, 1-10.

Shimosawa T, Ogihara T, Matsui H, Asano T, Ando K \& Fujita T. (2003). Deficiency of adrenomedullin induces insulin resistance by increasing oxidative stress. Hypertension 41, 1080-1085.

Shimosawa T, Shibagaki Y, Ishibashi K, Kitamura K, Kangawa K, Kato S, Ando K \& Fujita T. (2002). Adrenomedullin, an Endogenous Peptide, Counteracts Cardiovascular Damage. Circulation 105, 106-111.

Takamiya M, Miyamoto Y, Yamashita T, Deguchi K, Ohta Y, Ikeda Y, Matsuura T \& Abe K. (2011). Neurological and pathological improvements of cerebral infarction in mice with platinum nanoparticles. J Neurosci Res 89, 1125-1133.

Virtamo J, Rapola JM, Ripatti S, Heinonen OP, Taylor PR, Albanes D \& Huttunen JK. (1998). Effect of vitamin $\mathrm{E}$ and beta carotene on the incidence of primary nonfatal myocardial infarction and fatal coronary heart disease. Arch Intern Med 158, 668-675.

Vivekananthan DP, Penn MS, Sapp SK, Hsu A \& Topol EJ. (2003). Use of antioxidant vitamins for the prevention of cardiovascular disease: meta-analysis of randomised trials. Lancet 361, 2017-2023.

Watanabe A, Kajita M, Kim J, Kanayama A, Takahashi K, Mashino T \& Miyamoto Y. (2009). In vitro free radical scavenging activity of platinum nanoparticles. Nanotechnology 20, 455105.

Waypa GB, Marks JD, Mack MM, Boriboun C, Mungai PT \& Schumacker PT. (2002). Mitochondrial reactive oxygen species trigger calcium increases during hypoxia in pulmonary arterial myocytes. Circ Res 91, 719-726.

Wu QQ, Wang Y, Senitko M, Meyer C, Wigley WC, Ferguson DA, Grossman E, Chen J, Zhou XJ, Hartono J, Winterberg P, Chen B, Agarwal A \& Lu CY. (2011). Bardoxolone methyl (BARD) ameliorates ischemic AKI and increases expression of protective genes Nrf2, PPARgamma, and HO-1. Am J Physiol Renal Physiol 300, F1180-1192.

Xing G, Shimosawa T, Ogihara T, Matsui H, Itakura K, Qingyou X, Asano T, Ando K \& Fujita T. (2004). Angiotensin II-induced insulin resistance is enhanced in adrenomedullin-deficient mice. Endocrinology 145, 3647-3651. Epub 2004 Apr 3622. 
Yusuf S, Dagenais G, Pogue J, Bosch J \& Sleight P. (2000). Vitamin E supplementation and cardiovascular events in high-risk patients. The Heart Outcomes Prevention Evaluation Study Investigators. N Engl J Med 342, 154-160.

Ziegler D, Nowak H, Kempler P, Vargha P \& Low PA. (2004). Treatment of symptomatic diabetic polyneuropathy with the antioxidant alpha-lipoic acid: a meta-analysis. Diabet Med 21, 114-121. 


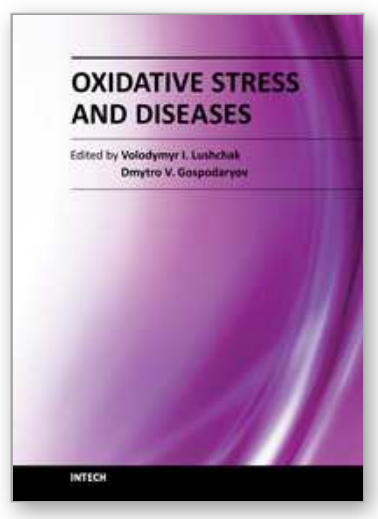

\author{
Oxidative Stress and Diseases \\ Edited by Dr. Volodymyr Lushchak
}

ISBN 978-953-51-0552-7

Hard cover, 610 pages

Publisher InTech

Published online 25, April, 2012

Published in print edition April, 2012

The development of hypothesis of oxidative stress in the 1980s stimulated the interest of biological and biomedical sciences that extends to this day. The contributions in this book provide the reader with the knowledge accumulated to date on the involvement of reactive oxygen species in different pathologies in humans and animals. The chapters are organized into sections based on specific groups of pathologies such as cardiovascular diseases, diabetes, cancer, neuronal, hormonal, and systemic ones. A special section highlights potential of antioxidants to protect organisms against deleterious effects of reactive species. This book should appeal to many researchers, who should find its information useful for advancing their fields.

\title{
How to reference
}

In order to correctly reference this scholarly work, feel free to copy and paste the following:

Tatsuo Shimosawa, Tomoyo Kaneko, Xu Qingyou, Yusei Miyamoto, Mu Shengyu, Hong Wang, Sayoko Ogura, Rika Jimbo, Bohumil Majtan, Yuzaburo Uetake, Daigoro Hirohama, Fumiko Kawakami-Mori, Toshiro Fujita and Yutaka Yatomi (2012). Oxidative Stress in Multiple Organ Damage in Hypertension, Diabetes and CKD, Mechanisms and New Therapeutic Possibilities, Oxidative Stress and Diseases, Dr. Volodymyr Lushchak (Ed.), ISBN: 978-953-51-0552-7, InTech, Available from: http://www.intechopen.com/books/oxidative-stress-anddiseases/oxidative-stress-in-multiple-organ-damage-in-hypertension-diabetes-and-ckd-mechanisms-and-newther

\section{INTECH}

open science | open minds

\author{
InTech Europe \\ University Campus STeP Ri \\ Slavka Krautzeka 83/A \\ 51000 Rijeka, Croatia \\ Phone: +385 (51) 770447 \\ Fax: +385 (51) 686166 \\ www.intechopen.com
}

\author{
InTech China \\ Unit 405, Office Block, Hotel Equatorial Shanghai \\ No.65, Yan An Road (West), Shanghai, 200040, China \\ 中国上海市延安西路65号上海国际贵都大饭店办公楼 405 单元 \\ Phone: +86-21-62489820 \\ Fax: $+86-21-62489821$
}


(C) 2012 The Author(s). Licensee IntechOpen. This is an open access article distributed under the terms of the Creative Commons Attribution 3.0 License, which permits unrestricted use, distribution, and reproduction in any medium, provided the original work is properly cited. 